\title{
Alergia látex-fruta
}

\section{Latex-fruit allergy}

Flávia Andréia MARIN

Suely Prieto de Barros Almeida PERES ${ }^{1}$

Antônio ZULIANI²

\section{RE S U M O}

O látex está sendo considerado o alergênico do ano 2000, tendo em vista que inúmeros indivíduos, principalmente profissionais da área de saúde e pacientes submetidos a várias intervenções diagnósticas e terapêuticas, estão freqüentemente expostos aos alérgenos do látex, presentes em produtos de borracha natural. As manifestações clínicas conseqüentes às reações alérgicas de hipersensibilidade imediata vão desde rinite, urticária, conjuntivite, angioedema, asma, até anafilaxia. Estudos recentes estão demonstrando que pacientes alérgicos ao látex desenvolvem concomitantemente sensibilização a certos alimentos de origem vegetal, especialmente frutas como papaia, figo, banana, abacate, kiwi, pêssego, abacaxi, melão e castanha, acreditando-se numa provável ocorrência de reações cruzadas entre os alérgenos do látex e destas frutas. Faz-se, então, uma revisão sobre a alergia ao látex, em particular sobre os grupos de risco, incluindo a presença de reatividade cruzada entre o látex e as frutas.

Termos de indexação: hipersensibilidade alimentar, látex, reatividade cruzada, frutas.

\section{A B S T R A C T}

The latex is being considered the allergenic agent of the year 2000, taking into account that several individuals, mainly health care professionals, and patients who had undergone many diagnostic and therapeutic interventions, are frequently exposed to latex allergens, which are present in natural rubber latex products. The clinical manifestations, derived from allergic reactions of immediate hypersensitivity vary from since rhinitis, conjunctivitis, urticaria, angioedema, asthma, to anaphylaxis. Recent researches are demonstrating that patients

\footnotetext{
1 Setor de Nutrição e Dietética, Hospital de Reabilitação de Anomalias Craniofaciais, Universidade de São Paulo (HRAC-USP). Setor de Nutrição do HRAC-USP. Av. Getúlio Vargas, 19-56, Jardim Europa, 17045-001, Bauru, SP, Brasil. Correspondência para/ Correspondence to: S.P.B.A. PERES.

2 Faculdade de Medicina da Universidade Estadual Paulista, Botucatu, SP.
} 
allergic to latex develop concomitantly sensitization to certain vegetable foods, especially fruits like papaya, fig, banana, avocado, kiwi, peach, pineapple, melon and chestnut, and a probable occurrence of cross reaction between allergens of latex and of these fruits is believed. A review is made about latex allergy, in particular about risk groups, including the presence of cross-reactivity between latex and fruit.

Index terms: food hypersensitivity, latex, cross-reactivity, fruit.

\section{N T R O D U ÇÃ O}

A alergia ao látex representa uma importante ameaça à saúde em países industrializados, devido ao uso freqüente de produtos de borracha natural (Fuchs et al., 1997).

Durante os últimos anos, descobriu-se que o látex tem estado freqüentemente envolvido nas reações de hipersensibilidade imediata (Latasa et al., 1995). Estas reações alérgicas são mediadas por imunoglobulinas E (IgE) específicas para os antígenos do látex. Há portanto, um risco potencial crescente para os indivíduos constantemente expostos a produtos elaborados com este componente (Rueff et al., 1998; Yagami et al., 1998), principalmente para os profissionais da área de saúde (Alemohammad et al., 1995; Palczynski et al., 1997; Mace et al., 1998), podendo-se assim, caracterizar a alergia ao látex como uma doença ocupacional (Taylor \& Praditsuwam, 1996).

Tal fato pode ser atribuído ao surgimento da Síndrome da Imunodeficiência Adquirida (AIDS), a qual ocasionou aumento da paramentação nos profissionais da saúde, proporcionando uma maior exposição aos alérgenos do látex (Weesner Junior, 1997), principalmente o contato com luvas de borracha (Aichane et al., 1997).

A primeira reação de hipersensibilidade imediata ao látex foi descrita por Stem em 1997, na Alemanha (Ebo et al., 1997). Desde então, esta substância tem sido relacionada com urticária generalizada, rinite, conjuntivite, asma e choque anafilático (Latasa et al., 1995). No Brasil, a prevalência de hipersensibilidade a este material não é ainda conhecida (Geller et al., 1997).
Relatos apontam a crescente incidência das reações alérgicas tipo I aos alérgenos do látex, os quais são de origem protéica e estão contidos nos componentes protéicos da seiva natural extraída da seringueira Hevea brasiliensis (Alemohammad et al., 1995). O látex ou seiva leitosa sofre um processamento, cujo produto final, contém um polímero de isopreno, CIS - 1, 4 - Poliisopreno, com 2\% a 3\% de proteínas (Mourão \& Rosário Filho, 1995).

Os polipeptídeos são conhecidos como a principal causa de reações de hipersensibilidade imediata (Chen et al., 1997), demonstradas através de testes cutâneos por puntura (Skin Prick Test), testes de liberação de histamina do basófilo, e, ainda, testes in vitro. Estes procedimentos objetivam identificar anticorpos IgE específicos, e os principais são: Radio Allergo Sorbent Test (RAST), Eczyme Linked Imuno Sorbent Assay (ELISA) e lgE immunoblots (Kelly et al., 1994; Ebo et al., 1997; Diez-Gomez et al., 1998; Groot et al., 1998).

O principal alérgeno do látex é a Heveína (Hev b 1), fator de alongamento da borracha, que é um polipeptídeo com peso molecular correspondente a 14,6 Kd (Chen et al., 1996; Yeang et al., 1996). Outro importante alérgeno é a Hev b 3, proteína com peso molecular de $24 \mathrm{Kd}$. Estes polipeptídeos são responsáveis pela produção de IgE específicos para o látex (Alenius et al., 1996; Yeang et al., 1996) .

\section{Mecanismos Imunológicos}

Segundo Mourão \& Rosário Filho (1995), as reações ao látex ocorrem por mecanismos de 
hipersensibilidade do tipo I e IV de Gell e coombs.

As reações alérgicas do tipo I ou de hipersensibilidade imediata, como já citado anteriormente, são mediadas por anticorpos da classe IgE. Tais reações ocorrem devido à estimulação dos mastócitos teciduais e seus análogos na circulação, os basófilos. A ativação de mastócitos e basófilos é iniciada mais caracteristicamente quando o antígeno específico aglutina as moléculas IgE na superfície pré-fixada destas células. Desta forma, a seqüência típica de eventos na hipersensibilidade imediata é a seguinte: produção de IgE pelos linfócitos $\mathrm{B}$ em resposta à primeira exposição a um antígeno, chamada sensibilização, ligação da $\lg$ E a receptores específicos nas superfícies de mastócitos e basófilos e interação do antígeno reintroduzido com a IgE ligada, levando à ativação das células e liberação de mediadores (Abbas et al., 1998).

As manifestações clínicas e patológicas de hipersensibilidade do tipo I, podendo ser cutâneas, pulmonares ou sistêmicas, são conseqüentes às ações de mediadores liberados, os quais causam patologias como: rinite, conjuntivite, urticária, asma bronquial, angioedema e anafilaxia sendo esta última a forma mais extrema de manifestações sistêmicas, cujos mediadores podem restringir as vias respiratórias ao ponto de asfixia e produzir um colapso cardiovascular, levando ao óbito (Rojido, 1993; Abbas et al., 1998).

As reações alérgicas do tipo IV ou de fase tardia ocasionam manifestações cutâneas como: eczema de contato (por luvas), dermatites de contato (por roupas ou preservativos), estomatite de contato (por utensílios odontológicos). Elas também têm sido freqüentemente divulgadas na literatura e têm sido atribuídas à sensibilização por aditivos químicos utilizados no processamento do látex natural, com destaque para o mercaptobenzotiazol e o tetrametiltiuram. A possibilidade de polipeptídeos serem responsáveis por estas reações não foi criteriosamente investigada (Rojido, 1993; Mourão \& Rosário Filho, 1995).

Quanto à prevalência de reações alérgicas do tipo I e IV em uma população de risco, Groot et al. (1998) relataram que 36,9\% dos indivíduos de uma amostra tiveram dermatite nas mãos, mas o patch test, específico para aditivos, foi positivo para apenas $6,6 \%$ destes, e reações alérgicas do tipo I, mediadas por IgE e demonstradas por testes cutâneos, estiveram presentes em $24,6 \%$ deles.

\section{Fatores que predispõem a hipersensibilidade ao látex}

A sensibilização pelo látex ocorre quando há um contato repetitivo, estimando-se ser necessário uma exposição de 6 meses a 15 anos para o seu desenvolvimento (López et al., 1995).

A exposição ao antígeno pode acontecer por diferentes vias, como cutânea, percutânea, mucosa e parenteral, e sua transferência ocorre pelo contato direto. No entanto, ultimamente, tem-se sugerido também a transferência por um contato indireto, como pela via aerossol (Mourão \& Rosário Filho, 1995; Castro \& López, 1996). Palczynski et al. (1997) relataram três casos de reações alérgicas severas ao látex em profissionais que trabalhavam na área de saúde. Um deles foi causado por um alérgeno inalatório, o outro aconteceu durante a realização de um exame profilático ginecológico e o último ocorreu ao encher um balão de borracha em casa.

Na literatura médica têm sido relatados, muitos casos inéditos de reações aos alérgenos do látex por contato direto, como o descrito por Mitxelena et al. (1998), no qual um paciente traqueostomizado apresentou dermatite de contato devido ao disco de borracha presente na cânula. Na Alemanha, Baur et al. (1998) reportaram dois casos de reações de hipersensibilidade local causada por balão de látex de um catéter esofagiano. Reações cutâneas e da mucosa oral, mediadas por mecanismos do sistema imunológico, foram associadas a materiais dentários por Hensten-Pettersen (1998). 
A origem deste problema é multifatorial (Castro Cué \& Cuanalo Dorantes, 1996), e entre os fatores de risco para ocorrência de reações alérgicas mediadas por lgE encontram-se: história clínica de sensibilidade ao látex, como a existência de dermatite de contato ou eczema nas mãos, ou, ainda, edema ou prurido após contato com produtos de borracha (Mourão \& Rosário Filho, 1995; Geller et al.,1997); quadro de alergia alimentar, principalmente a frutas (Beezhold et al., 1996; Brehler et al., 1997); atopia (Field, 1998).

Aichane et al. (1997) observaram uma prevalência de $81 \%$ de atopia em indivíduos alérgicos ao látex. Embora esta manifestação seja um fator de risco significante, sujeitos não atópicos também podem desenvolver sensibilidade a esta substância, como o caso de um menino caucasiano com 6 anos de idade, sem atopia conhecida, com reações de hipersensibilidade imediata para produtos de látex e frutas, relatado por Freeman (1997).

\section{Grupos de risco}

Estudos demonstram a existência de um vasto grupo de risco para desenvolver reações de hipersensibilidade ao látex, compreendido por indivíduos intensamente expostos aos alérgenos do látex, principalmente profissionais da área de saúde (Beezhold et al., 1996b; Rueff et al., 1998) e pacientes submetidos freqüentemente a meios diagnósticos e terapêuticos (Burrow et al., 1998).

Pacientes com meningomielocele (espinha bífida) são de alto risco, assim como aqueles com anomalias urogenitais congênitas, pois sofrem várias intervenções cirúrgicas que os expõem ao contato com o látex, sendo as manifestações alérgicas proporcionais ao número de intervenções cirúrgicas e à presença de atopia (Leonard et al., 1996; Ylitalo et al., 1997; Cremer et al., 1998).

Cremer et al. (1998), estudando a prevalência de alergia ao látex em população com espinha bífida, demonstraram desenvolvimento de anticorpos IgE em 40,5\% dos pacientes, valor maior do que o encontrado no grupo de crianças atópicas $(11,4 \%)$ e no grupo controle $(1,9 \%)$.

Lebenbom-Mansour et al. (1997) detectaram, em um ambulatório cirúrgico de Michigan (USA), uma incidência de 6,7\% de anticorpos para o látex nos seus pacientes e concluíram ser um problema potencial significante nesta população.

Segundo Leonard et al. (1996), devido ao aumento de reações alérgicas para o látex, é necessário propor, primeiramente, uma estratégia para identificar o grupo de risco e, em seguida, submeter os indivíduos ao teste para diagnóstico. Avaliando vinte pacientes, 17 com meningomielocele e 3 com anomalia cerebral, foi confirmada a alergia ao látex em 11, concluindo-se que estas crianças apresentaram um risco elevado para hipersensibilidade ao látex.

Relatos recentes têm mostrado um crescente aumento na prevalência de reações alérgicas em trabalhadores com exposição ocupacional ao látex (Charous et al., 1994). A sensibilização ocorre mediante o contato com luvas cirúrgicas e outros produtos fabricados com a borracha natural de látex (Alenius et al., 1996).

Allmers et al. (1997) descreveram uma ocorrência de $22 \%$ de sensibilização tipo I em profissionais da área de saúde, estando incluídos na amostra médicos, enfermeiras, dentistas e auxiliares odontológicos ou de laboratório (Safadi et al., 1996; Camacho lbarra et al., 1997; Field, 1998). Já Mace et al. (1998) encontraram uma incidência de 6,9\% nas reações alérgicas ao látex em enfermeiras de centro cirúrgico, enquanto Aichane et al. (1997) constataram uma freqüência de 5,3\% em trabalhadores hospitalares.

Segundo Safadi et al. (1996), a prevalência de hipersensibilidade ao látex é semelhante tanto no grupo de odontologistas quanto nos demais profissionais da área de saúde. Estudando uma população de dentistas, verificou-se sensibilização aos antígenos do látex em $12 \%$ deles. Taylor \& Praditsuwan (1996) acrescentaram que as manifestações alérgicas apresentadas por este 
grupo são, freqüentemente, sintomas sistêmicos, eczema nas mãos e dermatite de contato.

Os trabalhadores de indústrias que fabricam produtos de borracha ou utilizam equipamentos de látex diariamente, devido ao alto grau de exposição, também podem desenvolver reação de hipersensibilidade ao látex, como encontrado por Rojido (1993) e Freeman (1997), com uma incidência de 6,2 a 11,0\% neste grupo.

Segundo Mourão \& Rosário Filho (1995), "a incidência de reações ao látex mediadas por lgE na população geral é desconhecida". No entanto, indivíduos não pertencentes aos grupos de risco citados podem se sensibilizar aos antígenos do látex, como um caso de anafilaxia apresentado por Ferreira et al. (1997), sem prévia identificação de fatores de risco.

\section{Reatividade cruzada entre látex e alimentos}

Recentemente muitos estudos têm associado a alergia ao látex com a alergia a alimentos. A hipersensibilidade para alguns gêneros alimentícios em pacientes alérgicos ao látex tem sido confirmada na literatura pela descrição de casos de anafilaxia após ingestão, principalmente de frutas, que ocorreu devido a presença de reações cruzadas entre os antígenos do látex e os contidos nestes alimentos (Monreal et al., 1996; Weiss \& Halsey, 1996).

Blanco et al. (1994b) sugeriram a existência da latex-fruit syndrome, antigenicidade cruzada do látex com as frutas, pelo fato de $52 \%$ dos pacientes avaliados, com alergia ao látex comprovada, apresentarem alergia a certas frutas, entre as quais as mais freqüentes foram abacate, castanha, banana, kiwi e papaia. As três primeiras demonstraram reatividade cruzada com o látex.

Provavelmente estas reações cruzadas entre o látex e algumas frutas sejam devidas à existência de antígenos comuns (Latasa et al., 1995), ou mesmo à presença no látex de uma lisozima, polipeptídeo que possui funções enzimáticas (peso molecular igual a $27 \mathrm{Kd}$ ) e tem similaridade com as lisozimas das frutas (Yagami et al., 1995).

Lavaud et al. (1995) investigaram os alérgenos do látex, do abacate e da banana, e encontraram um peso molecular semelhante nestes, aproximadamente $30 \mathrm{Kd}$, sendo confirmada, portanto, a ligação dos alérgenos a uma epítope comum presente em látex e frutas. Chen et al. (1997), pesquisando a reatividade cruzada do maior alérgeno do látex, a heveína, com proteínas do abacate, concluíram que a sensibilização depende exclusivamente das epítopes da Heveína. Sanchez-Monge et al. (1999) constataram em seus estudos que dois alérgenos (34 Kd e $32 \mathrm{Kd}$ ) são responsáveis por mais de $50 \%$ das reações alérgicas com a banana, enquando Delbourg et al. (1996) verificaram nesta fruta a presença de mais de dez componentes alergênicos comuns com o látex, sendo considerados seus principais alérgenos aqueles com peso molecular variando de $33 \mathrm{Kd}$ a $37 \mathrm{Kd}$.

Segundo Beezhold et al. (1996a), a reatividade cruzada com alimentos é comum, ocorrendo em 33 dos 47 indivíduos alérgicos ao látex submetidos a testes immunoblots. Os testes cutâneos para alimentos foram positivos para abacate, batata, tomate, castanha e kiwi, e os pacientes tiveram diferentes manifestações clínicas, inclusive anafilaxia, como também observado nos estudos de Blanco et al. (1994a) e de Latasa et al. (1995). Blanco et al. (1994a) investigaram a sensibilização ao látex em 17 pacientes com hipersensibilidade ao abacate e outras frutas e concluíram que 10 eram alérgicos ao látex, 8 à castanha e à banana, 4 às nozes e ao kiwi. De acordo com Latasa et al. (1995), embora pacientes com alergia ao látex possam desenvolver múltipla sensibilização a frutas, as mais comuns foram ao abacate e à banana, seguidos da castanha e do melão.

Brehler et al. (1997) avaliaram, através do RAST - testes de inibição, a ocorrência de reações cruzadas entre o látex e as seguintes frutas: papaia, abacate, banana, castanha, figo, melão, 
kiwi, abacaxi, pêssego e tomate. Encontrou-se, em $69,1 \%$ das amostras séricas de pacientes alérgicos ao látex, anticorpos IgE específicos para frutas, e 42,5\% apresentaram manifestações clínicas após ingestão. Posteriormente, Moller et al. (1998) demonstraram, através de testes de inibição immunoblots, que quase todos os alérgenos do látex, abacate e banana, e dois alérgenos do kiwi ( $43 \mathrm{Kd}$ e $47 \mathrm{Kd}$ ) compartilhavam epítopes lgE comuns.

Garcia et al. (1998), investigando a prevalência de alergia ao látex em pacientes alérgicos a frutas (melão, pêssego e banana) e com história precedente de reações com o látex, constataram sensibilização imunológica ao látex em $85,9 \%$ deles.

Já Diez-Gomez et al. (1998) estudaram pacientes portadores de asma persistente causada pelo contato com o látex de Ficus benjamina, os quais apresentaram também edemas de orofaringe e língua pela ingestão de figo e kiwi. Eles foram avaliados através dos seguintes testes: cutâneos, liberação de histamina, IgE específica e provocação brônquica. Observou-se uma associação positiva entre este tipo de látex e as frutas citadas, devido à existência de reações cruzadas entre os alérgenos.

Recentemente, Kim \& Hussain (1999) verificaram em 29 pacientes, dos 137 estudados com alergia ao látex diagnosticada através de testes cutâneos e/ou testes in vitro, reações alérgicas a 15 diferentes tipos de alimentos sendo banana, abacate, kiwi e tomate os mais freqüentes.

De acordo com alguns estudos, a freqüência de hipersensibilidade a alimentos em alérgicos ao látex, nos diferentes grupos de risco, compreende: $28,1 \%$ em profissionais da área de saúde (Aichane et al., 1997); 29,4\% especificamente no corpo de enfermagem de centro cirúrgico (Mace et al., 1998); e 35,0\% em pacientes com história de várias cirurgias, principalmente com espinha bífida (Leonard et al., 1996).

\section{CON CLUSÃO}

Segundo Castro Cué \& Cuanalo Dorantes (1996), a alergia ao látex tornou-se na atualidade uma nova problemática clínica, preocupando a comunidade médica internacional, pois estudos epidemiológicos feitos em estados membros da União Européia, assim como nos Estados Unidos, revelaram que $2 \%$ a $5 \%$ dos profissionais da área de saúde são alérgicos ao látex (Palczynski et al., 1997).

Considera-se como agravante desta questão a ocorrência de reações cruzadas entre os antígenos do látex e de certos alimentos, especialmente de frutas, como a síndrome látexfruta ou a alergia látex-fruta, sugeridas na literatura, devido à reatividade de proteínas similares, com mesmo peso molecular.

É recomendável uma avaliação in vivo dos indivíduos pertencentes aos grupos de risco, através de testes cutâneos por puntura (prick test), com antígeno para o látex e bateria de antígenos alimentares, porque o tratamento mais eficaz é a prevenção destes tipos de reações alérgicas, que tornaram-se uma preocupação crescente, tanto pela variedade do grupo atingido quanto pela gravidade de suas manifestações clínicas, e particularmente porque muitos casos sem etiologia permanecem ignorados e atribuídos a outras causas.

\section{REFERÊ NCIAS BIBLIOGRÁFICAS}

ABBAS, A.K., LICHTMAN, A.H., POBER, J.S. Mecanismo efetores das reações imunes iniciadas pela imunoglobulina E. In: ABBAS, A.K., LICHTMAN, A.H., POBER, J.S. Imunologia celular e molecular. 2.ed. Rio de Janeiro: Revinter, 1998. p.295-310.

AICHANE, A., BOUAYAD, Z., OUTMANI, A., AFIF, H., TROMBATI, N., BAHLAOUI, A. Latex allergy in a hospital setting: results of a study in Casablanca. Revue des Maladies Respiratoires, Paris, v.14, n.6, p.451-455, 1997. 
ALEMOHAMMAD, M.M., MALKI, J., FOLEY, T.J. Detection of IgE antibodies to latex allergens in human serum. Contact Dermatitis, Copenhagen, v.32, n.5, p.298-302, 1995.

ALENIUS, H., KALKKINEN, N., REUNALA,T., TURJANMAA, K., PALOSUO, T. The main IgE-binding epitope of a major latex allergen, prohevein, is present in its N-terminal 43-amino acid fragment, hevein. Journal of Immunological, Baltimore, v.156, n.4, p.1618-1625, 1996.

ALLMERS, H., HUBER, H., WIRTZ, C., KIRCHNER, B., RAULF-HEIMSOTH, M., BAUR, X. Exposure testing with powdered gloves in 60 health care workers with latex allergy. Deutsche Medizinische Wochenschrift, Stuttgart, v.122, n.43, p.1308-1312, 1997.

BAUR, X., CHEN, Z., KORN, M., MOLKENTHIN, A., NIODUSCHEWSKI, R., SCHNEIDER, E.M. Latex allergy: local hypersensitivity reaction caused by an esophageal catheter in compliance determination. Pneumologie, Stuttgart, v.52, n.1, p.24-25, 1998.

BEEZHOLD, D.H., SUSSMAN, G.L., LISS, G.M., CHANG, N.S. Latex allergy can induce clinical reactions to specific foods. Clinical and Experimental Allergy, Oxford, v.26, n.4, p.416-422, 1996 a.

BEEZHOLD, D., SWANSON, M., ZEHR, B.D., KOSTYAL, $D$. Measurement of natural rubber proteins in latex glove extracts: comparison of the methods. Annals of Allergy Asthma and Immunology, Saint Paul, v.76, n.6, p.520-526, 1996b.

BLANCO, C., CARRILLO, T., CASTILLO, R., QUIRALTE, J., CUEVAS, M. Avocado hypersensitivity. Allergy, Copenhagen, v.49, n.6, p.454-459, 1994a.

BLANCO, C., CARRILLO, T., CASTILLO, R., QUIRALTE, J., CUEVAS, M. Latex allergy: clinical features and cross-reactivity with fruits. Annals of Allergy, Bloomington, v.73, n.4, p.309-314, 1994b.

BREHLER, R., THEISSEN, U., MOHR, C., LUGER, T. "Latex-fruit syndrome": frequency of cross-reacting IgE antibodies. Allergy, Copenhagen, v.52, n.4, p.404-410, 1997.

BURROW, G.H., VINCENT, K.A., KRAJBICH, J.I., AIONA, M.D. Latex allergy in non spina patients: unfamiliar intra-operatie anaphylaxis. Australian and New
Zealand Journal Surgery, Carlton South, v.68, n.3, p.183-185, 1998.

CAMACHO IBARRA, V. del C., LOPEZ GARCIA, A.I., GARCIA, J.A., PAZ MARTINEZ, D., PAPAQUI TAPIA, J.S. Prevalence of latex hypersensitivity among medical personnel. Alergia México, México, v.44, n.6, p.150-152, 1997.

CASTRO, F.F.M., LÓPEZ, S. Asma por látex. Revista Brasileira de Alergia e Imunopatologia, São Paulo, v.19, n.2, p.55-57, 1996.

CASTRO CUÉ, A., CUANALO DORANTES, A. Alergia a látex un riesgo actual. Alergia Inmunologia Pediatrica, v.5, n.2, p.64-69, 1996.

CHAROUS, B.L., HAMILTON, R.G., YUNGINGER, J.W. Occupational latex exposure: characteristics of contact and systemic reactions in 47 workers. Journal of Allergy and Clinical Immunology, Saint Louis, v.94, n.1, p.12-18, 1994.

CHEN, Z., VAN KAMPEN, V., RAULF-HEIMSOTH, M., BAUR, X. Allergenic and antigenic determinants of latex allergen Hev b1: peptide mapping of epitopes recognized by human, murine and rabbit antibodies. Clinical and Experimental Allergy, Oxford, v.26, n.4, p.406-415, 1996.

CHEN, Z., POSH, A., LOHAUS, C., RAULF-HEIMSOTH, M., MEYER, H.E., BAUR, X. Isolation and identification of hevein as a major IgE-binding polypeptide in Hevea latex. Journal of Allergy and Clinical Immunology, Saint Louis, v.99, n.3, p.402-409, 1997.

CREMER, R., HOPPE, A., KORSCH, E., KLEINE-DIEPENBRUCK, U., BLAKER, F. Natural rubber latex allergy: prevalence and risck factors in patients with spina bifida compared with atopic children and controls. European Journal of Pediatrics, New York, v.157, n.1, p.13-16, 1998

DELBOURG, M.F., GUILLOUX, L., MONERET-VAUTRIN, D.A., VILLE, G. Hypersensitivity to banana in latex-allergic patients. Identification of two major banana allergens of 33 and $37 \mathrm{kd}$. Annals Allergy, Asthma and Immunology, Arlington, v.76, n.4, p.321-326, 1996.

DIEZ-GOMEZ, M.L., QUIRCE, S., ARAGONESES, E., CUEVAS, M. Asthma caused by Ficus benjamina 
latex: evidence of cross-reactivity with fig fruit and papain. Annals Allergy, Asthma and Immnology, Arlington, v.80, n.1, p.24-30, 1998.

EBO, D.G., STEVENS, W.J., BRIDTS, C.H., DE CLERCK, L.S. Latex-specific IgE, Skin testing, and lymphocyte transformation to latex in latex allergy. Journal of Allergy and Clinical Immunology, Saint Louis, v. 100, n.5, p.618-623, 1997.

FERREIRA, M.B., PEDRO, E., BARBOSA, P., CARLOS, A.G. Manifestações clínicas da alergia ao látex. Acta Medica Portuguesa, Lisboa, v.10, n.11, p.825-831, 1997.

FIELD, E.A. Atopy and other risk factors for UK dentists reporting an adverse reaction to latex gloves. Contact Dermatitis, Copenhagen, v.38, n.3, p.132-136, 1998.

FREEMAN, G.L. Cooccurrence of latex and fruit allergies. Allergy and Asthma Proceedings, Providence, v.18, n.2, p.85-88, 1997.

FUCHS. T., SPITZAUER, S., VENTE, C., HELIER, J., KAPIOTS, S., RUMPOLD, H., KRAFT, D., VALENTA, R. Natural latex, grass pollen, and weed pollen share IgE epitopes. Journal of Allergy and Clinical Immunology, Saint Louis, v.100, n.3, p.356-364, 1997.

GARCIA, J.C.O., MOYANO, J.C., ALVAREZ, M., $B E L L I D O, J$. Latex allergy in fruit-allergic patients. Allergy, Copenhagen, v.53, n.5, p.532-536, 1998.

GELLER, M., PAIVA, T.C.B. de, GELLER, P. Alergia ao látex mediada por IgE em centro cirúrgico. Revista Brasileira de Alergia e Imunopatologia, São Paulo, v.20, n.5, p.166-168, 1997.

GROOT, H., JONG, N.W., DUIJSTER, E., van GERTH, W.R., VERMEULEN, A., van TOORENENBERGEN, A.W., GEURSEN, L., van JOOST, T. Prevalence of natural rubber latex allergy (type I and type IV) in laboratory workers in the Netherlands. Contact Dermatitis, Copenhagen, v.38, n.3, p.159-163, 1998.

HENSTEN-PETTERSEN, A. Skin and mucosal reactions associated with dental materials. European Journal of Oral Sciencis, Copenhagen, v.106, n.2, p.707-712, 1998. (Parte 2).
KELLY, K.J., PEARSON, M.L., KURUP, V.P., HAVENS, P.L., BYRD, R.S., SETLOCK, M.A., BUTLER, J.C., SLATER, J.E., GRAMMER, L.C., RESNICK, A. A cluster of anaphylactic reactions in children with spina bifida during general anesthesia: epidemiologic fectures, risk factors, and latex hypersensitivity. Journal of Allergy and Clinical Immunology, Saint Louis, v.94, n.1, p.53-61, 1994.

KIM, K.T., HUSSAIN, H. Prevalence of food allergy in 137 latex-allergic patients. Allergy and Asthma Proceedings, Providence, v.20, n.2, p.95-97, 1999.

LATASA, M., DIEGUEZ, I., SANZ, M.L., PARRA, A., PAJARON, M.J., OEHLING, A. Fruit sensitization in patients with allergy to latex. Journal of Investigational Allergology and Clinical Immunology, Barcelona, v.5, n.2, p.97-102, 1995.

LAVAUD, F., PREVOST, A., COSSART, C., GUERIN, L., BERNARD, J., KOCHMAN, S. Allergy to latex, avocado, pear and banana: evidence for a 30kd antigen in immunoblotting. Journal of Allergy and Clinical Immunology, Saint Louis, v.95, n.2, p.557-564, 1995.

LEBENBOM-MANSOUR, M.H., OESTERLE, J.R., OWNBY, D.R., JENNETT, M.K., POST, S.K., ZAGLANICZY, K. The incidence of latex sensitivity in ambulatory surgical patients: a correlation of historical factors with positive serum immunoglobin E levels. Anesthesia and Analgesia, Stockholm, v.85, n.1, p.44-49, 1997.

LEONARD, J.C., MORIN, C., ALBECQ, J.F. Latex allergy and orthopedic surgery. Revue de Chirurgie Orthopedique at Reparatrice de Appareil Moteur, Paris, v.82, n.4, p.321-326, 1996.

LÓPEZ, S., DI DOMÊNICO, M.S.D.B., CASTRO, F.F.M. Alergia ao látex. Revista Brasileira de Alergia e Imunopatologia, São Paulo, v.18, n.4, p.126-129, 1995.

MACE, S.R., SUSSMAN, G.L., LISS, G., STARK, D.F., BEEZHOLD. D., THOMPSON, R., KELLY, K. Latex allergy in operating room nurses. Annals of Allergy Asthma and Immunology, Arlington, v.80, n.3, p.252-256, 1998.

MITXELENA, J., AGUIRRE, A., BILBAO, I., RATON, J.A., DIAZ-PEREZ, J.L. Contact dermatitis in a 
tracheostomized patient due to a rubber disc. Contact Dermatitis, Copenhagen, v.38, n.3, p.181-182, 1998

MOLLER, M., KAYAMA, M., VIELUF, D., PASCHKE, A., STEINHART, H. Determination and characterization of cross-reacting allergens in latex, avocado, banana and kiwi fruit. Allergy, Copenhagen, v.53, n.3, p.289-296, 1998.

MONREAL, P., SERVER, M.T., TORRENS, I., ESCODA, J.M. Hipersensitivity to fruits in latex allergic patients. Allergologia et Immunopathologia, Madrid, v.24, n.1, p.33-35, 1996.

MOURÃO, E.M.M., ROSÁRIO FILHO, N.A. Alergia ao látex. In: NEGREIROS, B., UNGIER, C. Alergologia clínica. São Paulo : Atheneu, 1995. p.389-397.

PALCZYNSKI, C., WALUSIAK, J., RUTA, U., GORSKI, P. Occupational allergy to latex: life threatening reactions in health care workers: report of three cases. International Journal of Occupational Medicine and Environmental Health, Lodz, v.10, n.3, p.297-301, 1997.

ROJIDO, G.M. Alergia al látex: un diagnóstico encubierto. Archivos Argentinos Alergia e Inmunologia Clínica, Buenos Aires, v.24, n.4, p.155-165, 1993.

RUEFF, F., THOMAS, P., REISSIG, G., PRZYBILLA, B. Natural rubber: latex allergy in patients not intensely exposed. Allergy, Copenhagen, v.53, n.4, p.445-449, 1998

SAFADI, G.S., SAFADI, T.J., TEREZHALMY, J.S., TAYLOR, J.S., BATTISTO, J.R., MELTON JUNIOR, A.L. Latex hypersensitivity: its prevalence among dental professionals. Journal of the American Dental Association, Chicago, v.127, n.1, p.83-88, 1996.

SANCHEZ-MONGE, R., BLANCO, C., DIAZ-PERALES, A., COLLADA, C., CARRIOLO, T., ARAGONCILLO, C., SALCEDO, G. Isolation and characterization of major banana allergens: identification as fruit class I chitinases. Clinical and Experimental Allergy, Oxford, v.29, n.5, p.673-680, 1999.
TAYLOR, J.S., PRADITSUWAM, P. Latex allergy: review of 44 cases including outcome and frequent association with allergic hand eczema. Archives Dermatology, Chicago, v.132, n.3, p.265-271, 1996.

WEESNER JUNIOR, B.W. Latex allergies and adverse reactions: a review of the literature. Journal of the Tennessee Dental Association, Nashiville, v.77, n.2, p.21-26, 1997.

WEISS, S.J., HALSEY, J.F. A nurse with anaphylaxis to stone fruits and latex sensitivity: potential diagnostic difficulties to consider. Annals of Allergy Asthma and Immunology, Arlington, v.77, n.6, p.504-508, 1996.

YAGAMI, T., SATO, M., NAKAMURA, A., SHONO, M. One of the rubber latex allergens is a lysozyme. Journal of Allergy and Clinical Immunology, Saint Louis, v.96, n.5, p.677-686, 1995. (Part 1).

YAGAMI, T., SATO, M., NAKAMURA, A., KOMIYAMA, T., KITAGAWA, K., AKASAWA, A., IKEZAWA, Z. Plant defense: related enzymes as latex antigens. Journal of Allergy and Clinical Immunology, Saint Louis, v.101, n.3, p.379-385, 1998.

YEANG, H.Y., CHEONG, K.F., SUNDERASAN, E., HAMZAH, S., CHEW, N.P., HAMID, S., HAMILTON, R.G., CARDOSA, M.J. The $14.6 \mathrm{Kd}$ rubber elongation factor ( $\operatorname{Hev~B~} 1)$ and $24 \mathrm{Kd}(\operatorname{Hev~b~3)}$ rubber particle proteins are recognized by $\mathrm{lg} E$ from patients with spina bifida and latex allergy. Journal of Allergy and Clinical Immunology, Saint Louis, v.98, n.3, p.628-639, 1996.

YLITALO, L., TURJANMAA, K., PALOSUO, T., REUNALA, $T$. Natural rubber latex allergy in children who had not undergone surgery and children who had undergone multiple operations. Journal of Allergy and Clinical Immunology, Saint Louis, v.100, n.5, p.606-612, 1997.

Recebido para publicação em 23 de maio de 2000 e aceito em 22 de março de 2001. 